\title{
Research on the Agro-technique Information Service Cloud Platform of Orchard Based on the Internet of Things(IOT)
}

\author{
Xiang Sun ${ }^{1,2,3,4, \text { a }}$, Huarui Wu $\mathrm{W}^{1,2,3,4, \mathrm{~b}^{\star}}$, Qingxue $\mathrm{Li}^{1,2,3,4, \mathrm{c}}$, Peng Hao $\mathrm{Ha}^{1,2,3,4, \mathrm{~d}}$ \\ ${ }^{1}$ Beijing Research Center for Information Technology in Agriculture, Beijing Academy of Agriculture \\ and Forestry Sciences, Beijing, 100097, China \\ ${ }^{2}$ National Engineering Research Center for Information Technology in Agriculture, Beijing 100097, \\ China \\ ${ }^{3}$ Key Laboratory of Agri-informatics, Ministry of Agriculture, Beijing 100097, China \\ ${ }^{4}$ Beijing Engineering Research Center of Agricultural Internet on Things, Beijing 100097, China \\ aemail:sunx@nercita.org.cn, ${ }^{\mathrm{b}} \mathrm{email}$ :wuhr@nercita.org.cn ( ${ }^{*}$ corresponding author), ${ }^{\mathrm{c} e m a i l:}$ \\ liqx@nercita.org.cn, ${ }^{\mathrm{d} e m a i l: ~ h a o p @ n e r c i t a . o r g . c n ~}$
}

Keywords: The Internet of Things; Cloud Services Platform; Orchard; Agricultural Information Services

\begin{abstract}
Aiming at the problems of high cost of orchard agro-technique information service, and service channel is not smooth, a "IOT and cloud services" mode platform architecture of orchard information service was established, which is including networking aware transport layer, storage layer, service layer and application layer. Several platform construction key technologies are discussed. The platform has four sub platform, they are orchard data gathering, orchard production management, farm management and agricultural products circulation management providing information service for agro-techniques from production to circulation. Through the application analysis, the platform can not only gather resources provide a knowledge service for the promotion of agricultural technology, and provide technical support for the scientific management of orchard, also can effectively reduce the base information financial and human input.
\end{abstract}

\section{Introduction}

The orchard production in our country is mainly based on extensive management. Science and technology information resources docking difficulties, the network channel, expert consultation hotline and other public service platform built by government and scientific research institutions have not been very good application[1].

Lacking of agricultural technology personnel, weak of the farmers' knowledge accept ability; lack of professional technical guidance in the production restricts the development of fruit industry.

The application of IOT and cloud computing technology to the management of the orchard, collecting and processing the data of the production environment, guiding the agricultural production, has become an effective way to solve the extensive management of the orchard[2,3].

In this paper, the agro-technique information service cloud platform of orchard was designed based on "Internet of Things and cloud service" mode. The platform integrates of the orchard management technology, knowledge model, market information, etc. Through the platform for rapid processing, and the use of the Internet, SMS, WeChat and other means, for farmers to provide with anywhere information services, significantly improve the grass-roots agricultural technology extension and service ability.

\section{Platform Architecture}

Agro-technique information service cloud platform of orchard is composed of the networking aware transport layer, storage layer, service layer and application layer, as shown in figure 1. 


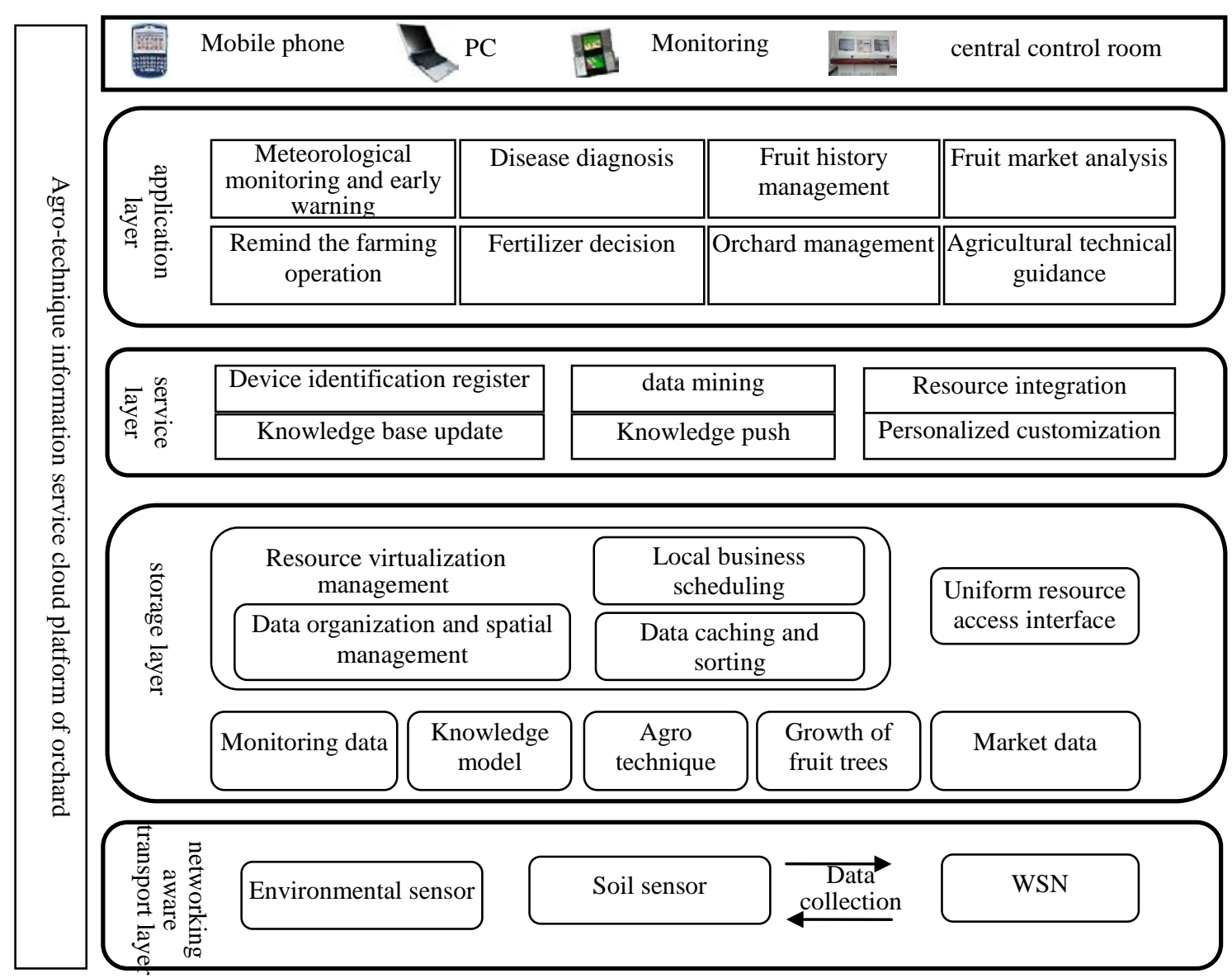

Figure. 1 Platform architecture

Networking aware transport layer: Integrated orchard environment and soil sensors, access to water saving irrigation, environmental control equipment, sensing data collected by the wireless sensor network sink node, through GPRS, Ethernet interface to realize the data communication with the platform [4].

Storage layer: Brought together orchard management knowledge resources, technical resources, the orchard sensor monitoring data, fruit trees growth information, and achieve to various kinds of data resource scheduling, registration, fast retrieval; as a service through a network of highly virtualized hardware facilities resources, data resources, services, resources accurately and quickly available to the user.

Service layer: According to the resource needs of different users, intelligent distributes the resources that according to the demand of classification (monitoring data, fruit market, management knowledge, growth model, the meteorological information service). Used in the field of agricultural information service oriented, providing different professional application interface and directory service, for the realization of the equipment management, fault tolerant data processing, analysis of knowledge mining, personalized custom, knowledge pushed.

Application layer: Based on the customized directional information service, through the mobile phone, PC, monitoring equipment and control of large screen to provide users the service, such as orchard monitoring, agricultural production, operation and management, fruit market which guidance and supporting of fruit production.

\section{Platform Key Technology}

There are several key technical problems need to be solved in the process of building the platform:

\section{Orchard Equipment Management}

The main task of the orchard data acquisition is to obtain the field environment, soil, video and image data through the equipment. Therefore, it is needed to provide a standardized access interface 
for the equipment to realize the rapid registration [5].

Equipment registration information includes \{classification, name, parameter, function introduction, interface standard, location, access time, manager. The manager can manage the equipment on-line, record the space distribution and usage of the equipment, query the information of the equipment, in accordance with the time, geographical, equipment types, the types of orchards and other dimensions, statistical equipment operating status and data collection, etc.

\section{Perceptual data exchange based on JSON}

Ajax technology using XML data exchange format will bring the transmission efficiency and security issues. This paper adopts the "Ajax + JSON + jQuery" IOT sensing data transmission scheme.

JSON is a simple data exchange format of JavaScript language subset, each object consists of a set of keys to define. For example: \{"air temperature": 17.5, air humidity: 67.1\}, ":" is the representation of attributes and values tips. "," separate each attribute, "\{" and " $\}$ " are the representation of object starting and ending. Because JSON and Map class in the JAVA can be very good corresponding to simplify the JSON process in the JAVA environment.

Table 1 is a comparison of XML and JSON format code examples.

Tab. 1 code comparison of XML and JSON

\begin{tabular}{|c|c|}
\hline XML format & JSON format \\
\hline <environment data $>$ & \{“environment data": \\
\hline$<$ orchard $1>$ & \{“orchard 1": \\
\hline <equipment1> & \{ \\
\hline <air temperature>17.5 & \{“air temperature”:17.5, \\
\hline$</$ air temperature $>$ & “air humidity”:67.1, \\
\hline$<$ air humidity $>67.1$ & "illumination intensity":3.8, \\
\hline </air humidity > & “carbon dioxide”:529, \\
\hline$<$ illumination intensity $>3.8$ & “soil temperature:14.1, \\
\hline$<$ /illumination intensity $>$ & “soil moisture content”:51.1 \\
\hline$<$ carbon dioxide>529 & \} \\
\hline$<$ carbon dioxide $>$ & \} \\
\hline <soil temperature>14.1 & \} \\
\hline$</$ soil temperature $>$ & \} \\
\hline \multicolumn{2}{|l|}{$<$ soil moisture content $>51.1$} \\
\hline \multicolumn{2}{|l|}{$</$ soil moisture content $>$} \\
\hline \multicolumn{2}{|l|}{ <equipment1> } \\
\hline \multicolumn{2}{|l|}{$<$ orchard $1>$} \\
\hline \multicolumn{2}{|l|}{$</$ environment data $>$} \\
\hline 322 byte & 177 byte \\
\hline
\end{tabular}

Compared with XML, JSON has advantages in simplicity, rapidity and space., The same data transmission, the use of XML requires $322 \mathrm{~B}$, and JSON needs $177 \mathrm{~B}$, reducing the amount of data transmission of $145 \mathrm{~B}$, when the transmission of large data can effectively improve the response speed, improve system performance.

\section{Multi-tenant application service based on SaaS}

Platform to achieve a multi-tenant application services model [6,7]. Data storage can be used in the following three ways:

The first is the use of independent database. Each orchard has a database. This data isolation method is the highest level of security, but the highest cost.

The second is part public of the database. Data isolation from the logic, that part of the isolation, some public, this way to save the platform to calculate the cost of resources, the disadvantage is that when there is a fault, the data recovery hard. 
The third is the shared database and data frame. Multiple users to share the same Database, the same Schema, through the table for different users to distinguish the Tenant ID to distinguish the data, this way to share the highest level, the lowest level of isolation. But the data backup, restore is tedious, need a table or record set of backup and restore.

The platform of the operating data storage considers using the first way; the public data storage considers using the third way.

\section{Platform information service visualization}

Web GIS and visualization technology combined cultivation of fruit trees, fertilizer, environmental monitoring and data management, management personnel timely accurately grasp the orchard distribution, production information provide a visual means, so as to improve the efficiency of management of the orchard.

Application of BlazeDS(Message Forwarding Middleware) to realize the mutual communication between Java application and Flex application. From the database query related data, converted to binary data based on the AMF protocol, and then the binary stream data submitted to the Flex front desk parsing. All kinds of data through the line chart, pie chart, hot spots, and other forms of display.

Map visualization of orchard distribution: The distribution of sensors is closely related to the geographical position. It is very difficult to understand the real situation of the orchard field. The data from the global perspective is needed to analyze the spatial data.

Three dimensional visualization of orchard scene: First collected related data, such as the remote sensing image, fruit trees texture data, sensing devices data, attribute data, and then use 3ds Max modeling software in a scene on the base of integrated modeling.

According to the model classification and production order from the Max 3DS modeling software for FBX format data, imported into the Unity3D development environment, the entire base model is integrated in a unified virtual scene.

\section{Platform Function}

The platform is divided into four systems: data aggregation system, production management system, management system and circulation management system of the orchard.

Orchard data aggregation system: with the IOT information collection equipment as the terminal, the integration of sensor data, text, pictures, audio and video and other unstructured data, to achieve the organization and management of these data. Remote monitoring and control of soil and meteorological environment monitoring equipment and wireless irrigation valve controller by PC or mobile phone [8].

Orchard production management system: the system realizes the monitoring and warning of the production environment data, the temperature and humidity suitable situation analysis, the disease and insect pest early warning, the management decision-making, the remote diagnosis analysis. Experts can online management of meteorological early warning model, growth model, pest damage early warning model, and timely dissemination of agricultural guidance information; expert according to the field data and description information, combined with the video camera to capture images, remote technical guidance and diagnostic services.

Orchard management system: provides two types of services for agricultural workers, orchard management service, achieve a to-do list, daily affairs, rules and regulations of the management, set up a sales records, covering orchard production data and product purchase, sale in domestic market, purchasing, sales, inventory, order management; the second is management of cooperatives in daily production record and records, management of fruit trees in different growth stages of the farming operation information, improve the management efficiency of the orchard.

Circulation of orchard management system: statistical analysis of fruit products supply and demand, price data, such as comparing some kind of fruit products in different regions of the price trend, the market supply and demand trend, through personalized pushed to the users who are need. 


\section{Application of the Platform}

The platform provides agricultural information services for the national 45 orchards.

Among them, an orchard in Fangshan District Beijing access to the 12 observation points of the meteorological and video monitoring equipment, 1 times / hour of environmental data acquisition and 1 times / day of crop image data acquisition. Through the platform services to guide the orchard's day-to-day production activities and established remote interactive space with viticulture experts, provide timely production, plant protection knowledge service.

Using platform orchard service statistics grape growth in the process of active accumulated temperature, effective accumulated temperature, rainfall, monitoring the ripeness of the grapes, provide decision-making basis for the optimal harvest time of grape and improve the wine grape quality raw materials.

In addition, base and technical personnel will be through the service platform obtained different planting area of small climate environmental data and monitoring points in each period growth picture data, farming management data, and various regions of different varieties of grapes yield and quality data of comprehensive analysis and analysis results of a year of farming plans (such as pluvial using wind and rain shelter cultivation technology, air set, drainage ditches settings, etc.) and management scheme (seasonal recruit temporary workers, agricultural equipment purchase, etc.) formulation provides effective support.

Also platform analysis the environmental data, the growth period of crop picture data, farming management data in different planting areas, various regions of different varieties of grapes yield and quality data, guiding next year farming plans (such as pluvial using wind and rain shelter cultivation technology, air set, drainage ditches settings, etc.) and management scheme (seasonal recruit temporary workers, agricultural equipment purchase, and so on).

"Cloud services +IOT" platform service model can effectively reduce the orchard of capital investment, human input in information construction. As table 2 shows , orchard do not need to put a server, network and software infrastructure equipment purchase by orchard service model of cloud platform and application software development and integration, maintenance personnel costs, and traditional information construction compared to at least reduce 64 thousand Yuan of funds investment.

Tab.2 comparison of informatization investment

\begin{tabular}{llll}
\hline \multicolumn{1}{c}{ Investment } & Traditional way & Cloud platform mode & Amount (ten thousand yuan) \\
\hline 1 PC & $\sqrt{ }$ & $\mathrm{O}$ & 0.5 \\
1 UPS & $\sqrt{ }$ & $\mathrm{O}$ & 0.2 \\
1 OS & $\sqrt{ }$ & $\mathrm{O}$ & 0.9 \\
1 Application software & $\sqrt{ }$ & Customized by platform & 2.0 \\
Hardware and software & $\sqrt{ }$ & Registered by the & 1.0 \\
integration & platform hardware & 1.0 \\
Maintenance fee & $\sqrt{ }$ & O & \\
Monitoring equipment & $\sqrt{ }$ & $\sqrt{ }$ & 0.8 \\
\hline
\end{tabular}

In this mode, the labor input of the orchard was saved about 8 months, and the work efficiency and quality were improved. 
Tab. 3 comparison of labor cost inputs

\begin{tabular}{|c|c|c|c|c|}
\hline $\begin{array}{c}\text { Comparative } \\
\text { content }\end{array}$ & Style & Range & Time & $\begin{array}{l}\text { Annual savings } \\
\text { in labor (day) }\end{array}$ \\
\hline \multirow{2}{*}{ Plant growth survey } & Manual collection & 12 observation points & 3(h) & \multirow{2}{*}{200} \\
\hline & Automatic collection & 12 observation points & $3(\mathrm{~s})$ & \\
\hline \multirow{2}{*}{$\begin{array}{l}\text { Soil moisture } \\
\text { monitoring }\end{array}$} & Laboratory analysis & 12 observation points & $8(\mathrm{~h})$ & \multirow{2}{*}{20} \\
\hline & Automatic collection & 12 observation points & $3(\mathrm{~s})$ & \\
\hline \multirow{2}{*}{ Work plan release } & $\begin{array}{l}\text { Rely on experience, on-site } \\
\text { guidance }\end{array}$ & Orchard Manager & $1(\mathrm{~h})$ & \multirow{2}{*}{15} \\
\hline & $\begin{array}{l}\text { Early development, mobile phone } \\
\text { alerts }\end{array}$ & Orchard Manager & $1(\mathrm{~s})$ & \\
\hline \multirow{2}{*}{$\begin{array}{l}\text { Technical guidance } \\
\text { and training }\end{array}$} & Expert on site training & Orchard Manager & $5(h)$ & \multirow[b]{2}{*}{5} \\
\hline & Online training & $\begin{array}{l}\text { Remote training / } \\
\text { mobile guidance }\end{array}$ & $3(h)$ & \\
\hline
\end{tabular}

\section{Conclusion}

In this paper, the IOT and cloud services technology is applied to the orchard management, to achieve accurate acquisition of environmental data, to realize data collection transmission through the wireless sensor network, to process the data and knowledge through the platform, to push the accurate guidance information for farmers. The platform has for Beijing, Henan, Shandong, Chongqing and other 45 orchards provide resource acquisition, network transmission, personalized service, to explore the information service mode of low cost.

Through the platform application analysis, estimation can reduce the informationization construction of production base invested 64 thousand Yuan of funds by the cloud service model, saving labor input 8 man-month, to achieve a "multi channels, flexible network terminal, whenever and wherever possible information service" service means, "lease type, zero investment, low threshold, no maintenance" service mode, suitable for the characteristics of the agricultural production, such as orchard production flow operation and large scope of work, provide technical support for scientific management of orchard management.

\section{Acknowledgement}

This work was supported by Special Fund for Agro-scientific Research in the Public Interest (201303107).

\section{References}

[1] Qiu Y, Fan J, Hu L, et al. Research on the "Three Networks in One" Orchard Production Information Service System[J]. Advances in Information \& Communication Technology, 2013, 392:1-10.

[2] Qin X L, Luo W, Yu-Ping L I, et al. Design cloud-based information service platform for tropical agriculture[J]. Guangdong Agricultural Sciences, 2014:65-84.

[3] Cui Y, Liu S. Key Technology Study of Agriculture Information Cloud-Services[M]. Computer and Computing Technologies in Agriculture V. Springer Berlin Heidelberg, 2011:313-317.

[4] Xu L, Liu S, Li D. Key Technology of South Sea Pearl Industry Management Information Service Platform Based on the Internet of Things[C]. Computer and Computing Technologies in Agriculture. 2011:479-490.

[5] Cheng Gongxun,Liu Lilan,Lin Zhiqi,Yu Tao. Intelligent Cloud Service Platform for Customer Preference[J]. China Mechanical Engineering. 2012,23(11):1318-1323,1336.

[6] Sun Xiang;Wu Huarui;Li Qingxue. Design and implementation of the massive agricultural information resource management platform $[\mathrm{J}]$. Computer Applications and Software, 2015(3):75-79. 
[7] Yan Xiaojun, Wang Weirui, Liang Jianping. Application mode construction of internet of things (IOT) for facility[J].Agriculture in Beijing Transactions of the Chinese Society of Agricultural Engineering, 2012, 28(04):149-154.

[8] Qian Jian-Ping,Xing Bin,Wu Xiao-Ming,Yang Xin-Ting,etc. Digital Orchard Management System[J].Computer Systems \& Applications, 2012(09):14-18. 